Dr Hawkey points out that Somerville et at calculated that 200 deaths a year are attributable to these drugs in Britain.: This is not so; the pape estimated that 200 deaths a year from peptic ulcer haemorrhage occur due to non-steroidal antiinflammatory drugs. This figure did not include deaths from perforation or sudden deaths occur ring at home." Estimates as high as 3000-4000 deaths a year from peptic ulcer complications associated with use of non-steroidal anti-inflammatory drugs have been made." Clearly this would considerably alter the cost effectiveness of coprescribing an ulcer healing drug.

Morbidity from peptic ulcers must also be taken into account. In a recent drug surveillance study based in Tayside 57715 prescriptions for nonsteroidal anti-inflammatory drugs issued to 25959 patients were analysed by record linkage." In patient morbidity from upper gastrointestinal events was compared with that in community controls. Non-steroidal anti-inflammatory drug takers were shown to be more likely to develop gastrointestinal symptoms or disease. The relative risk for women was 1.67 and for men 1.28 Extrapolation from the data in this study indicates that non-steroidal anti-inflammatory drugs potentially cause 15000 serious gastrointestinal event (perforation or haemorrhage) yearly in the United Kingdom. In addition many patients develop a simple gastric ulcer and considerably more have less severe gastroduodenal damage.

There is now evidence that gastroduodena damage can be prevented by coprescribing misoprostol," and it is therefore likely, but not proved, that the complications and mortality from peptic ulceration in users of non-steroidal antiinflammatory drugs can be reduced. Coprescribing an ulcer healing drug may be both beneficial to the patient and cost effective."

A L BLOWER

Hope Hospital, Salford $1168 \mathrm{HL}$

Hawkey CJ. Non-steroidal anti-inflammatory drugs and peptic ulcers. Br.Med f 1990;300:278-84. (3 February.)

2 Somerville K, Faulkener (, , Langman MJS. Non-steroidal antiinflammatory drugs and blecding peptic ulcer. Lance $1986 ; i: 462-4$

3 Blower AL. Armstrong CP. Sudden deaths at home from peptic ulceration-a hitherto unrecognised phenomenon. (iu 1986:27: A1281.

+ Armstrong CP, Blower AI.. Non-steroidal anti-inflammator drugs and the life threatening complications of peptic ulcer tion. (iut 1987:28:527-32.

5 Armstrong CP, Whitelaw S. Death from undiagnosed peptic ulcer complications: a continuing challenge. Br. 7 Surg 1988 $75: 1112-4$

6 Blower AL, Armstrong CP. Uker perforation in the elderly an non-steroidal anti-inflammatory drugs. Lancet 1986;: 971 .

Cockal R. NSAIDs - should every prescription carry a government health warning. (itut 1987;28:515-8.

8 Beardon PHD, Brown SV, McDeritt DG. Gastrointestinal events in patients prescribed non-steroidal antiinflammatory drugs: a controlled study using record linkage in Tayside. ().J Med 1989;71:497-505.

9 (iraham DY, Agrawal NM, Roth S. Prevention of NSAII) induced gastric ulcer with misoprostol: multicentre, double blind placebo-controlled trial. Lancet 1988:i1:1277-80.

10 Hillman AL, Bloom BS. Economic effects of prophylactic use of misoprostol to prevent gastric ulcer in patients taking nonsteroidal anti-inflammators drugs. Arch Intern. Med 1989:149 $2061-5$.

AUTHOR's REPLY, - The Tayside study' was published after my review was written but supports the points I made. It generates an estimate of relative risk of $2 \cdot 11$ ( $95 \%$ confidence interval 1.77 to $2 \cdot 51$ ), a figure rather lower than the average quoted in my article. Apparently higher rates of absolute risk than those in case control studies of ulce bleeding arise because the International Classification of Disease codings used would have included bleeding which was trivial, incidental to admission, originating from parts of the gastrointestinal tract other than the stomach or duodenum or from lesions other than ulcers, as well as misdiagnoses of gastrointestinal bleeding such as haemoptysi (P H G Beardon, personal communication) Calculations of absolute risk based on a $10 \%$ mortality are thus invalid. Because it has small numbers of younger patients the Tayside study leaves open the important question of whethe elderly patients are particularly sensitive to non-steroidal anti-inflammatory drugs as opposed to particularly prone to ulceration.

Although my article was not principally about individual drugs, Dr Shield points out that misoprostol can prevent gastric and duodenal erosions caused by ibuprofen. He points out that gastric crosions are more common than duodenal injury. However, as Graham and Smith remarked, "The clinician therefore should not be greatly concerned by the presence of gastric erosions associated with the acute administration of any drug given, because the extent and degree of such changes have no proven value for predicting the frequency and severity of these erosions, chronic ulcer or overt GI bleeding.'

On this basis most of the lesions portrayed in Dr Shield's dottogram are those with which the clinician "should not be greatly concerned." In the ibuprofen study there were $3 / 30$ acute gastric ulcers and 1/30 acute duodenal ulcers on placebo with none on misoprostol. In the tolmetin study $13 / 30$ patients on placebo, $4 / 30$ patients on cimetidine, and $0 / 29$ on misoprostol developed gastric ulcers while corresponding figures for duodena ulceration were $3 / 30,0 / 30$, and $0 / 29$. The reduc tions in tolmetin induced gastric ulceration by both cimetidine and by misoprostol were statistically significant, but any other comparisons of ulcer incidence in these studies were not. Moreover, it is not clear that these reductions are necessarily clinically important. The high incidence of lesion classified as ulcers supports my original argumen that lesions classified as ulcers in these studies are unlikely to be as dangerous as ulcers not associated with non-steroidal anti-inflammatory drugs when viewed in the context of epidemiological studies such as the ones Dr Shield quotes.

I do not agree that protecting the stomach is more (or indeed less) important than protecting the duodenum. Likewise, in practical terms most clinicians will have to deal with non-steroidal antiinflammatory drug takers who have presented with ulceration. No study has specifically investigated this very important problem, but studies which include patients with pre-existing ulcers probably have more relevance to the prescriber, rather than less.

My article refrained from making recommendations about prophylaxis. in view of the discrepancies of the data which it was written to highlight. While there may be commercial pressures to wish to believe that there is a large and easily prevent able problem in a conveniently identifiable group, assessment of all available data still suggests tha these are genuinely open questions. It is importan to identify questions which remain unanswered because this highlights areas where continuing research is desirable. This should not be construed as representing an implied commentary on the merits of competing commercial products.

$\mathrm{Mr}$ Blower's points are in agreement with the essential arguments of my article - that estimates of risk are widely discrepant. His data were included in the meta-analysis from which the epidemiological estimates of risk quoted were derived.

Gastroduodenal damage induced by nonsteroidal anti-inflammatory drugs can undoubtedly be prevented by prostaglandins. Specific prophylaxis of lesions which are likely to bleed is less certain, while prevention of complications has not been shown for any drug. Prophylaxis targeted specifically at bleeding is as worth exploring as prophylaxis targeted at mucosal injury.

In $\mathrm{Mr}$ Blower's study 26 patients had bleeding gastric ulcers and 69 had bleeding duodenal ulcers while in Graham et al's misoprostol trial of prophy laxis of acute lesions ${ }^{+}$the vast majority had gastric lesions, two more sets of facts which do not add up.
It would be a mistake to regard Graham et al's successful prophvlaxis of acute gastric lesions as a guide to prophylaxis of the chronic duodenal lesions which predominated in Mr Blower's study.

One way round this dilemma would be to postulate that non-steroidal anti-inflammatory drug induced haematemesis and melaena arise in whole or part because the drugs provoke bleeding in preexisting chronic ulcers. As prophylaxis of acute non-steroidal anti-inflammatory drug induced bleeding, manoeuvres which raise intragastric $\mathrm{pH}$ appear to be as successful as prostaglandins.' We have explored the possibility that normal clinical doses of the drug ethamsylate might reduce aspirin induced bleeding. ${ }^{\circ}$ Although the results failed to reach statistical significance, higher doses might yield better results and the general approach deserves further investigation. This is too important an area for premature conclusions to blight continuing research.

Department of Therapeutics,
University Hospital,

C J HAWKEY

Nottingham NG7 2UH

I Beardon PHG, Brown SV, McDevitt DG. (Gastrointestinal events in patients prescribed non-steroidal anti-inflammatory drugs: A controlled study using record linkage in Tasside. $Q \mathrm{f} \mathrm{Med}$ 1989:266:497-505.

2 Graham DY, Smith JL. Aspirin and the stomach. Ann Intern.Med 1986; 104:390-8.

3 Armstrong CP, Blower AL. Non-steroidal anti-inflammatory drugs and the life threatening complications of peptic ulceration. Gut 1987;28:527-32.

4 (iraham DY, Agrawal NM, Roth SH. Prevention of NSAID) induced gastric ulcer with misoprostol-a multicentre, double-blind, placebo-controlled trial. Lancet 1988;ii:1277-80.

5 Hawkey CJ, Somerville KW, Marshall S. Prophylaxis of aspirin nduced gastric mucosal bleeding with ranitidine. Alimentury Pharmacologv and Therapeutics 1988;2:245-52.

6 Stein A, Daneshmend TK, Bhaskar NK, Hawkey CJ. Failure of cthamsylate to reduce aspirin induced gastric mucosal bleeding in humans. Br f Clin Pharmacol 1989;28:109-12.

\section{Electrical arcing and contact lenses}

SIR, - Welding arcs and high voltage electrical flashovers are powerful sources of light of many wavelengths. They may damage the eyes of anyone, especially if suitable screens, goggles, or glasses are not used. Arc eye or welder's flash (keratitis photoelectrica) is caused by damage to the corneal epithelium, which absorbs light in the ultraviolet wavelengths. After a latent period severe pain ensues but the epithelium soon regenerates and there is usually no residual damage.

Most contact lenses do not protect against arc eve. Furthermore, they absorb energy from parts of the ultraviolet and infrared spectrums, and the resultant rise in temperature may cause them to adhere temporarily to the eye. Lövsund et al, using thick hydrogel lenses, showed that a rise of $810^{\circ} \mathrm{C}$ above the temperature of the surrounding air was produced in five minutes. ${ }^{\prime}$ The effect could be minimised by the use of an industrial screen. In actual lens wear tear flow and blinking could be expected to moderate the rises in temperature.

There have been reports of severe electric arc damage to workers' eves in many countries since the 1960s. One much repeated story arose after a shipyard incident in the United States in 1977, though the official inquiry established contact lens overwear as the cause. A common variant of this tale appeared in a national newspaper in May 1989.: It was comprehensively denied by the Health and Safety Executive two days later. The story will undoubtedly continue to surface from time to time - as Minerva has discovered ${ }^{+}$- sometimes innocently propagated by overcredulous industrial health advisers.

Contact lens wearers who are exposed to electric arcs should use the same recommended eye protection as those who do not use lenses and should blink frequently. If aphakic they should wear 